\title{
Participatory Design Strategies to Enhance the Creative Contribution of Children with Special Needs
}

\author{
Laura Malinverni ${ }^{1}$, Joan Mora-Guiard ${ }^{1}$, Vanesa Padillo ${ }^{2}$, Maria-Angeles Mairena ${ }^{2}$, \\ Amaia Hervás ${ }^{2}$, Narcis Pares ${ }^{1}$ \\ (1) Universitat Pompeu Fabra \\ Cognitive Media Technologies group, \\ ICT Department \\ c. Roc Boronat, 138 \\ +34 935422201 \\ laura.malinverni, joan.mora, \\ narcis.pares@upf.edu \\ (2) Hospital Sant Joan de Déu \\ Unidad Especializada en Trastornos del Desarrollo \\ (UETD) \\ Passeig Sant Joan de Déu, 2 \\ 08950 Esplugues de Llobregat \\ +34932532100 \\ vpadillo, mmairena, ahervas@hsjdbcn.org
}

\begin{abstract}
In recent years there has been an increasing awareness about the importance of involving children with special needs in the process of designing technology. Starting from this perspective, the paper presents the participatory design process carried out with children with autistic spectrum disorder for the design of a Kinect motionbased game aimed at fostering social initiation skills. By describing the strategies used for the design of the activities, we will suggest possible approaches aimed toward widening the space for contributions of children and including them at a more creative level. Within that, major emphasis will be dedicated to discussing the "empowering dimension" of participatory design activities as an instrument to enhance benefits both for design results and for the children themselves. Finally, the balance between structure and freedom in the design of the activities will be discussed.
\end{abstract}

\section{Categories and Subject Descriptors}

H.5.2. [Information Interfaces and Presentation (e.g., HCI]: User Interfaces - theory and methods, user-centered design.

\section{General Terms}

Design, Human Factors

\section{Keywords}

Participatory Design, Design Method, Autistic Spectrum Disorder, Children, Empowerment.

\section{INTRODUCTION}

In the last decades there has been an increasing awareness about the importance of involving children in the process of designing technology [19]. This awareness is founded on the acknowledgement that children are an entirely different user population with their own culture, norms, complexities and preference [8].Their contributions are therefore crucial for the development of a technology that is capable of properly addressing their specific needs and interests. From this

Permission to make digital or hard copies of all or part of this work for personal or classroom use is granted without fee provided that copies are not made or distributed for profit or commercial advantage and that copies bear this notice and the full citation on the first page. Copyrights for components of this work owned by others than the author(s) must be honored. Abstracting with credit is permitted. To copy otherwise, or republish, to post on servers or to redistribute to lists, requires prior specific permission and/or a fee. Request permissions from permissions@acm.org.

IDC'14, June 17-20, 2014, Aarhus, Denmark.

Copyright is held by the owner/author(s). Publication rights licensed to ACM.

ACM 978-1-4503-2272-0/14/06 ...\$15.00.

http://dx.doi.org/10.1145/2593968.2593981 perspective, a number of different methods have been proposed to involve children in the design process, such as: user-centered design, contextual design, participatory design, informant design and cooperative inquiry [23].

Within this context, in recent years, an increasing interest has been posed on the possibilities of involving children with special needs into the design process. As Frauenberg points out, it is often this population that can benefit the most from design process that include them [13]. However, this approach can often present challenges related with properly defining the role that these children can assume in the design process. As Guha et al. point out, the appropriate level of involvement begins with researcher's expectations and it is influenced by the nature and the severity of the child's disability and the quality of the available support [15]. Defining the role of children represents a delicate issue since we move in the continuum between overwhelming the child and relegating him in a marginal role, in which his skills are not fully considered.

Starting from this perspective, this paper presents the participatory design (PD) process carried out with children with autistic spectrum disorder (ASD) for the design of a Kinect game aimed at fostering social initiation skills. During the unfolding of the workshop, the level of involvement of the children has been gradually redefined through the continuous observation of their responses. This iterative process of evaluation and adjustment of the proposed activities, together with the use of a set of narrativebased techniques, allowed widening the space for children contributions and including them at a more creative level.

The description of the gradual transformation of the level of involvement of children in the design process will offer a novel contribution to research oriented at involving children with special needs in participatory design. At the same time, the discussion of the tools and techniques used will provide specific suggestions and "concepts to think about" [19] when we design PD activities for children with special needs. Within that, major emphasis will be dedicated to discussing the "empowering dimension" of participatory design activities as an instrument to enhance benefits both for design results and for the children themselves. Finally the balance between structure and freedom in the design of the activities will be discussed. 


\section{PARTICIPATORY DESIGN WITH AUTISTIC CHILDREN}

Autism is a neurodevelopment disorder characterized by delayed or abnormal functioning in social interaction, social communication and symbolic play and restrictive or repetitive interests and sensory abnormalities [3]. Within these, many researchers suggested that the social impairment may represent the most important deficit [28]. However, the use of appropriate educational interventions can improve quality of life of ASD children [25,27]. Given these premises a number of interactive systems have been developed to help ASD children to learn and practice social interaction skills [2,5,17,26,29,31].

Within this context, an increasing awareness has been placed on the importance of involving end-users in the design process to better understand their needs and preferences. Starting from this necessity, different approaches leading to different methods have been used, e.g.: children involvement as testers, participation via proxy, or direct involvement of children as informants [11].

The involvement of ASD children as informants has been reported by several authors $[4,10,12,13,16,20]$, which propose different methods. Methods vary from efforts to get feedback from children about design choices $[10,20]$, to the analysis of their preference [13], the creation of scenarios [20] or the observation of their behavior $[13,16]$. The incorporation of these methods permits integrating children's contributions directly into the initial design stages, allowing a deeper influence on the definition of the final product.

However, as Benton points out, much of the previous research in this area has focused on the benefits for design results rather than the potential benefits for the children themselves. When we involve children in a participatory design process, it is fundamental to carefully consider whether the defined activities are capable of engaging, motivating and inspiring them [19]. This means that, when we design with children, we don't have to take into account only the extent to which an activity can produce useful design results, but also to evaluate whether the activity can be enjoyable for children.

At the same time, another important aspect that we considered to be fundamental in the selection of activities for the PD process, is their "empowering dimension". This "empowerment dimension" should include the analysis of two main aspects: the extent to which children care about what they are doing (meaningfulness) and their perception about the relevance and importance of their contributions (feeling of competence). These aspects are particularly important when we work with children. According to Erikson's theory of psychosocial development, children between 6 and 12 years, need to experience situations in which they can demonstrate their competencies, tracking their achievements and feel that they are capable of doing stuff: if children are encouraged and reinforced they may start to feel industrious and confident [22]. This aspect is even more important when we collaborate with children with special needs, since this population tends to be underrepresented in decision-making processes and often, the focus on "needs" reduces the attention that can be placed on "skills". It is therefore fundamental to facilitate conditions in which they feel that their capabilities are recognized and that they are skilled for doing relevant and important things.

\section{PROJECT DESCRIPTION}

The project has been developed in the frame of the M4All European project. Its main goal is to develop a set of motionbased playful learning experiences for children with learning difficulties. Within this context, our goal is to develop a Kinectbased game for children with ASD to help them acquire simple abilities in social interaction. For this purpose we focus our design strategy on an informant model, aimed at involving different stakeholders during the different stages of the project [30]. According to this framework we structured the design process in two consequent stages. First, through collaboration with experts, we defined the educational goals of the project. Second, we carried out a participatory design with children to transform defined goals into an enjoyable playful experience.

\subsection{Goals definition}

To define the goals of the project we collaborated with experts of the "Specialized Unit on Developmental Disorders" (UETD) of the Sant Joan de Déu Children's Hospital in Barcelona. The requirements elicitation process was carried out through multiple meetings with the psychologists and psychiatrists of the UETD. A detailed description of the requirement elicitation process is reported in [21].

Through these meetings, we decided to focus the main goal of the project on promoting social initiation, understood as the promotion of behaviors such as approaching and asking for help to others, starting social communication and producing any verbal or gestural behavior for communicative goals. In order to achieve this goal the psychologists defined a short treatment plan based on four sessions. These four sessions are organized to progressively incorporate increasingly complex social initiation abilities to achieve interaction and collaboration with others. For this purpose the UETD professionals defined a set of objectives that constitute behavioral skills, which need to be addressed within traditional treatment related with fostering social initiation.

The main goal of the game was therefore to work as a mediator of social communication. This approach requires the design of situations that are either valuable for the children to feel the need to communicate about them, or that require the child to look for external collaboration. This main requirement posits the central necessity of merging the therapeutic techniques, used to facilitate social initiation, with the interests and preferences of children. To address this issue we planned five participatory design workshops aimed at integrating children perspective in the game design.

\subsection{From goals to playful experience: defining the participatory design activities}

The main goals of the PD were: (1) validate a set of initial design proposals derived from UETD professionals' requirements; (2) gather new ideas from children; (3) evaluate which aspects elicit higher level of motivation and interest in children. On a transversal view, PD activities were designed by taking into account two main aspects: the use of an educational design research approach in the definition of the activities and the creation of a feeling of continuity and progression between the different sessions.

\subsubsection{Educational design research approach}

Educational design research is defined by Van den Akker as a research method focused on improving the effectiveness of educational interventions through progressive approximations. It is characterized by being an interventionist, iterative and process- 
oriented approach, which focuses its analysis on the integral phenomenon and not on the isolation of variables [32]. This approach implies adopting a research method based on continuous adjustments and iterations, which depends on the ongoing evaluation of the effectiveness and impact of the interventions.

Applying this approach to the design of PD activities implies embedding flexibility in the design of the structure of the workshops. This means to be able to constantly evaluate the impact of the proposed activities and to adjust them accordingly to ongoing observations. Mazzone et al., proposed two dimensions for evaluation of the PD activities: suitability and capability. Suitability is defined as the extent to which the proposed activities are capable of engaging, involving and inspiring children as active participants in the process. On the other hand, capability represents the extent to which the activities can produce useful results for the design [19]. At the same time we added a novel evaluation dimension into our analysis: the empowerment dimension. The evaluation of this dimension implies to consider the extent to which children care about what they are doing (meaningfulness) and their perception about the relevance and importance of their contributions (feeling of competence). .

The evaluation was carried out on two levels:

- During the session the engagement and contributions of the children were taken into account in order to define the effectiveness of the activities and eventually modify them (withinsession adjustments).

- After each session, the opinions of the psychologist and the observations of the researchers were combined to improve the design of the following session (between-session adjustments).

\subsubsection{Feeling of continuity and progression}

Several examples of PD with children with ASD address the design of the activities as discrete units [13] that can often seem decontextualized and poorly related between them. We believe that a feeling of continuity and progression between the different activities would be beneficial to ground their contributions on a common terrain and to foster their involvement. To address this necessity we applied two main methods: (1) the use of an underlying narrative structure and (2) the use of personalized storage boxes.

\subsubsection{The narrative structure}

The use of narrative in PD activities is a widely acknowledged practice, capable of supporting inquiry on specific issues, fostering engagement and facilitating collaboration with end-users [7]. This technique has often been used to provide a fictional layer, working as a pretext to address questions that otherwise could look odd or out of place [6,7]. However, in our case, instead of developing a narrative that is unrelated to the final application, we based the narrative structure on the backstory of the game, which was previously defined through the meeting with the psychologists. Following the Fictional Inquiry technique, workshop activities were structured around the plot of the backstory. Each workshop activity was designed to form part of a larger narrative structure and to address specific design questions. Two main techniques were used to promote a feeling of narrative continuity and progression:

1) Chapters and scene cards: Each workshop session was conceptualized as a chapter in the game backstory (see table 1). This structure was supported by the previous creation of "scene cards" in which the location, the child's targeted behavior and a series of possible conflicts were defined. Such method allowed organizing the workshop according to a progressively unfolding narrative, which we hypothesized, could help in grounding children's contributions on a common terrain and enhancing their attachment to the activities.

2) Cliffhangers: According to the chapter structure we used the narrative device of "cliffhangers" to foster the continuity between each workshop session. At the end of each session therefore the main character was confronted with a turning-point of the story, which would be solved only in the next workshop session. This device fostered children's curiosity since it helped to create a feeling of suspense about what would happen next.

\subsubsection{Storage material}

Another device to strengthen the feeling of continuity of the experience and the attachment to the activities was the use of a personalized storage box for each child. At the beginning of the workshop each child was provided with a box aimed at containing both their own artworks (i.e. drawings) and the reward badges they received after completing each activity. These reward badges were designed to remind them about the main aspects of the carried out activities.

The use of a personalized box is a widely acknowledged practice both in art education and in expressive art therapies [9] since it doesn't only provides storage, but more importantly, allows keeping track of one's own progress. We hypothesized that the use of this device could help children feel their progress and competence through the unfolding of the workshops.

Table 1: workshop sessions and chapters

\begin{tabular}{|c|c|c|}
\hline SESSIONS & SCENE CARD & $\begin{array}{l}\text { CHAPTER (Workshop } \\
\text { activities) }\end{array}$ \\
\hline 1 & $\begin{array}{l}\text { Location: wood } \quad \text { planet } \\
\text { Earth); day /Targeted } \\
\text { behavior: } \text { start interaction }\end{array}$ & $\begin{array}{l}\text { Introducing the main } \\
\text { character }\end{array}$ \\
\hline 2 & $\begin{array}{l}\text { Location: wood (planet } \\
\text { Earth); day /Targeted } \\
\text { behavior: start interaction / } \\
\text { Conflict: antagonists }\end{array}$ & $\begin{array}{l}\text { Build a relation with } \\
\text { the main character; } \\
\text { help it }\end{array}$ \\
\hline 3 & $\begin{array}{l}\text { Location: wood (planet } \\
\text { Earth); night /Targeted } \\
\text { behavior: } \\
\text { activity with a familiar adult }\end{array}$ & $\begin{array}{l}\text { Help the character to } \\
\text { build and fuel its } \\
\text { spaceship; travel back } \\
\text { to its planet }\end{array}$ \\
\hline 4 & $\begin{array}{l}\text { Location: alien's planet } \\
\text { /Targeted behavior: joint } \\
\text { attention } / \quad \text { Conflict: } \\
\text { antagonists }\end{array}$ & $\begin{array}{l}\text { Help the character to } \\
\text { find its friend }\end{array}$ \\
\hline 5 & $\begin{array}{l}\text { Location: alien's planet / } \\
\text { Targeted behavior: turn } \\
\text { taking/Conflict: antagonists }\end{array}$ & $\begin{array}{l}\text { Meeting with the } \\
\text { friend; celebration }\end{array}$ \\
\hline
\end{tabular}

\section{PARTICIPATORY DESIGN WORKSHOP}

The workshop took place in a dedicated room of the Sant Joan de Déu Children's Hospital on a weekly basis. The participants selected by the UETD professionals were four children (A, B, C 
\& D) diagnosed within the Autism Spectrum Disorder, all males between 9 and 10 years old. All four children present normal cognitive capabilities, functional language and have been enrolled together in a previous social skill training group during one course in the UETD. Hence, they had a good bond with the therapist and between themselves. Child A presents some inabilities with oral expression, alteration of prosody, proneness to distraction and disconnection from the activities. Child B presents symptomatology of motor restlessness, impulsivity and difficulties in focusing attention. Child $\mathrm{C}$ presents good verbal expression competences and is participative and collaborative. However, he has an anxious socio-emotional base and a lack of ability to manage his emotions, which is controlled with medication. Child D presents symptoms associated to Attention deficit hyperactivity disorder (ADHD), specific learning problems and sleep problems, which are controlled with medication.

Despite their age did not fit with the target users ( $\sim 5-6$ years old), the UETD professionals considered that this developmental level (both in chronological and functional age) was more suitable for participatory design (PD) activities. Moreover, the UETD professionals considered that informing these children about the fact that they would be participating in the design of a videogame for younger children would have a beneficial effect at two main levels:

- $\quad$ firstly, by motivating them through the attribution of a role of responsibility and,

- $\quad$ secondly, by fostering the perspective-taking exercise of trying to figure out preferences of younger children.

A total of five sessions were carried out. During each session three researchers and a psychologist were present. All children were already familiar with the psychologist and the environment. Each session lasted for one hour and was designed to address specific aspects of the game design. For the analysis of each session direct observation and video analysis were used.

Direct observation was carried out by a psychologist and a researcher who took written field notes. Videos were analyzed after the sessions and relevant behaviors and utterances were transcribed. Material from video transcription and note taking was therefore coded by a researcher into two main categories:

- Design choices: understood as children's contributions to specific design aspects, such as: objects to appear in the environment, organizational aspects of the objects, color choices, etc.

- Affective aspects: understood as children's expressions related with how much they liked the activities and their level of enjoyment and motivation.

Data from this analysis was later discussed by the whole team and used to inform both the design of the game and the planning of the following PD activities. In the following sections we provide a short description of the used activities and relevant observations.

\subsection{First session}

The first session was aimed at introducing ourselves and the project to the children. We explained them that they would help us in designing a video game for younger children and that the aim of the game was to enjoy playing between friends. We started the session with the presentation of the game backstory: "a friendly alien arrives to the Earth by mistake; the child has to help it travel back to its planet to meet its friends again". After that we set-up a series of activities aimed at defining the alien's features. These activities had two goals: (1) to investigate the possibility of including the customization of the alien as part of the game, and (2) to facilitate the involvement of the children in the workshop by establishing a relationship with the main character.

According to Fullerton, videogame characters cover two main functions: agency and empathy. Agency refers to the practical function of the character, while empathy is the potential for players to develop an emotional attachment to it [14]. Agency was already defined by the requirements of the UETD professionals; therefore we framed children's contributions around the definition of a believable and likeable character aimed toward fostering empathy. Children were asked to propose its name and were instructed that the alien can change its aspect depending on the food it eats. Hence, they proposed its food preference (Fig.1) and invented specific customizations related with the ingestion of specific food. To carry out these activities several low-tech materials were used such as: a little puppet theatre that worked as a scaled prototype of the virtual environment of the game (Fig. 2), causal tables of relations between food and effect and cut-outs of the different elements (Fig. 3). The materials were either produced by the researchers or derived from online resources of materials for special needs.

\subsubsection{Observations}

From the first session it was clear that the children were much more motivated, participative and creative than what we had been warned about and, hence, expected. A clear example of this was found in the use of causal tables. Causal tables were derived from resources of augmentative communication and based on a triptych structure. In these tables children had to indicate the initial state of the character, the food that it eats and the consequent transformation. A number of different models of causal tables were presented. Each one offered different levels of required completion, which ranged from having the initial and final state already defined (therefore allowing the children to choose only the food) to completely empty tables in which children were asked to fill all the stages. Children were instructed on how to fill each one of the tables and the different templates were made freely available to them. Children were asked to choose a preferred template to work with. Children generally preferred to work with empty tables, and ended up using a large amount of these. A possible explanation can be found in the fact that these templates allowed them to design a full new range of transformation possibilities. This observation suggested that children could better enjoy less constrained activities, since they were clearly more motivated by the possibility of inventing their own "worlds" and "situations". This allowed us to define the activities of the following sessions from a broader and more creative perspective.

At a design level the session allowed us to get a better understanding of two main aspects: (1) the fundamental role of the previous knowledge that children had on the language of cartoons and videogames as effective mediators of interaction metaphors and (2) the definition of the logic behind the transformation and customization of the character. The analysis of their proposals showed that character transformations should be highly discrete, self-evident and meaningful. Furthermore, the relation between food eating and transformation should be mainly based either on visual or on functional properties of the food (e.g. obtaining a "fire outfit" if the alien eats chili, turning its skin green if it eats lettuce, etc.). Children were especially motivated and engaged by transformations related with super-powers derived from their audiovisual culture (e.g. "super armor", "ice breath", etc.). 


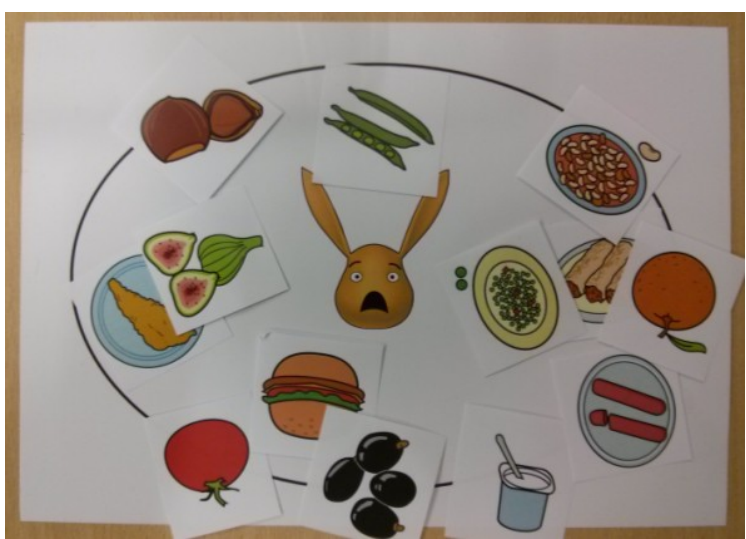

Figure 1. Definition of food's preference using emotional expression

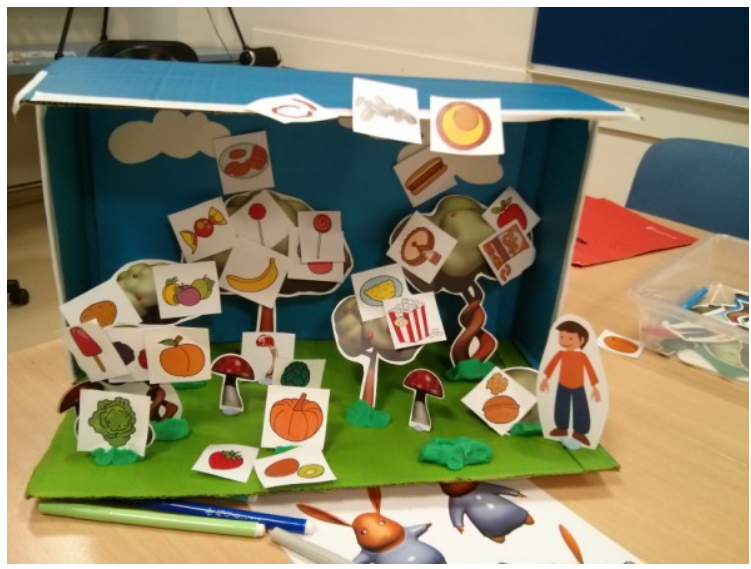

Figure 2. Puppet theatre

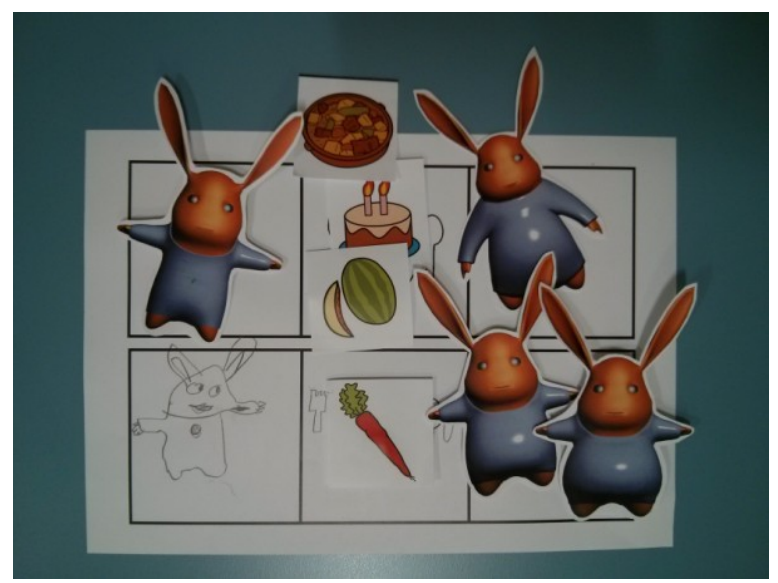

Figure 3. Causal tables and cut-outs

\subsection{Second session}

The second session was aimed at observing the intuitiveness of the interaction with the Kinect device, define the character's behavior and design its spaceship. From the experience gained in the previous session we defined the activities in order to allow more freedom for children's creativity and contributions.

We introduced the activities as a second chapter of the story: the alien has already eaten and now it needs to plan how to go back to its planet. The session was divided into two main parts: a first part dedicated to motor activity and a second part dedicated to drawing. To introduce the first part we started with a short warmup activity based on reciprocal imitation of movements. After that, children were introduced to the game through the use of a Wizard-of-oz system which allowed starting a basic interaction with the elements (Fig.4). The set up of the Wizard of Oz was based on a Kinect camera and a standard television screen in order to emulate the final configuration of the game set-up. The child could see himself inserted in the virtual environment, in a thirdperson interaction paradigm typical of Kinect-based games (Fig. 4) [24]. An operator remotely controlled the interaction with the environment (e.g. activating the fall of a food when the child passed his hand over it) and grossly simulates the behavior of the alien (e.g. moving it toward the food). Being at an initial stage, neither animation, visual or sound effects were present. Children were invited to play in a single user mode while the others were involved in a drawing activity.

Subsequently, children were asked to start a short role-play activity in which, by turns, one child had to interpret the player and the other the alien. To guide this activity we used a step outline structure based on asking behavior related questions: e.g. "What would happen if the child did not pay attention to the character?" Meanwhile, the children that were not role-playing were asked to make a drawing of what they thought the spaceship of the character would look like.

\subsubsection{Observations}

The creation of a narrative thread between the different sessions and the central role assumed by the character allowed making it and its story a central reference for the contributions of the children (e.g. "this is the friend of the alien", "this is its spaceship", "it will seat here to drive"), facilitating conditions for a proper orchestration of the requirements and preferences of children. At the same time the use of a chapter structure fostered the curiosity of children on what would happen next.

From a design perspective the observation of their interaction with the virtual environments allowed us to find more intuitive ways to design the interaction. The use of role-play allowed us to define certain behaviors of the character and its expected reaction to the input of children. Children showed especially strong preference for highly expressive reactions in character behavior. Another important observed aspect was that one child felt uncomfortable seeing his own image represented on the screen. This finding suggested the possibility of adding a customization parameter to the application that would allow changing the visual representation of the player; e.g. from a fully detailed camera image to a plain simple silhouette.

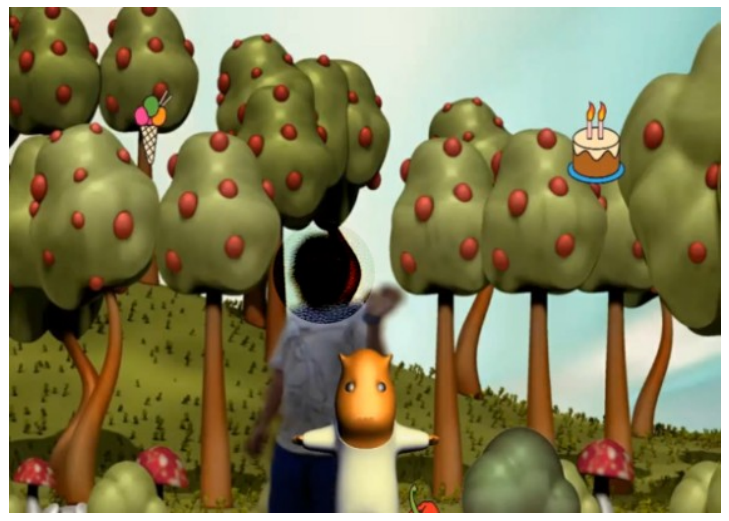

Figure 4. Child playing with a Wizard of $\mathrm{Oz}$ of the game 


\subsection{Third session}

The third session aimed at exploring which kind of situations require the collaboration of others and analyzing game mechanics related recovering and fueling the alien's spaceship. Unfortunately two children were unable to attend this third session and one child spent half the session going out of the room to see his father.

We tried to introduce the activities by explaining that the alien's spaceship was out of fuel and therefore they need to help him in fixing it. However, due to the changes in the dynamics caused by the absence of two children, the participants were poorly motivated to pay attention to the instructions. We therefore choose to quickly change the expected activities and involve the children in physical games that could be more suitable to deal with their lack of involvement. Through the use of low-tech materials, we made the children play a set of physical games proposed by the designers as possible mechanics to recover and fuel the spaceship. All the proposed mechanics were based on the need for collaboration to solve a certain task. For example, catching small "energy balls" (actually ping-pong balls) by putting their hands together as if forming a container-like structure. Finally, we asked them to rate the likeability of these physical games.

The quick change in the nature of the activity proved to be a good choice, since a climate of dialogue, enjoyment and participation was re-established. At a design level, even if we didn't manage to facilitate conditions for novel contributions, the session allowed us to evaluate the enjoyability of different game mechanics for this level. More importantly this experience showed the fundamental role of a flexible structure and the central necessity of researchers to be tuned and receptive to the affective state of children.

\subsection{Fourth session}

The fourth session aimed at exploring the visual aspects of the alien's planet and the game mechanics related to helping the character to find its friends. In contrast to the first session, in which the visual appearance of the environment was already provided to the children, we choose to avoid directing their contributions and give them the freedom to draw the planet as they imagined it (Fig. 5). Despite some authors suggest that children with ASD may feel distressed when confronted with a completely blank sheet of paper [20], according to our previous observations we hypothesized that this method could be beneficial to foster their willingness to contribute and their feeling of competence.

Although they were all in the same room sharing the experience, children were asked to draw the planet on their own, without communicating their design choices to the others. This approach was chosen because, in the previous sessions, sometimes we had noticed a stronger leadership of one child who tended to influence the opinions of the others. After they had all finished their drawings, each child presented his drawings to the others. Then, we introduced a turning-point in the story: "a mysterious accident happened in the planet and all the spaceships of its inhabitants are now trapped". Through the use of directed design technique children were asked to suggest what is trapping the spaceships and how we can free them by collaborating between two children. A researcher drew their suggestions on a blackboard (Fig. 6).

\subsubsection{Observations}

This session was particularly productive and engaging for children. Several creative solutions were proposed for the design of the planet. By allowing a higher level of freedom in the imagination of children, this method was found to be particularly suitable in terms of engagement, if compared with the use of cutout pre-designed materials (as in session 1). Children gave detailed explanations of their drawings, showing a certain level of excitement in explaining their ideas (e.g. asking us "Would you put this in the game?"). Two children asked whether they could to go show their drawings to their parents, suggesting a feeling of "being proud" of their artworks.

This activity however, in terms of its capability to provide concrete design solutions, caused some difficulties when integrating the highly different proposals. To overcome this issue we focused on extrapolating common features from children's proposals and give the planet an anachronistic appeal.

The directed design activity was highly effective in stimulating children collaboration. Several design ideas were proposed and children were highly motivated in specifying their ideas to allow the researchers understand them to draw them properly. Quite interestingly, during this activity, a misunderstanding with a word led the researcher to draw a "thorny sauce" ("salsa espinosa") instead of a "thorny bush" ("zarza espinosa"). This mistake produced great enjoyment in the children and facilitated the proposal of novel and less conventional ideas (e.g. "Spaceship are trapped in giant sandwiches and we need to collaborate to eat all the sandwich"). Furthermore, the "thorny sauce" anecdote became thereafter a sort of leitmotif for playful social interaction with the researcher, suggesting possible ideas about the design possibilities of "designerly mistakes".

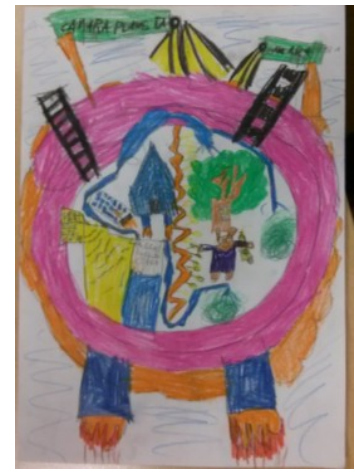

Figure 5. Drawing of a planet produced by one child

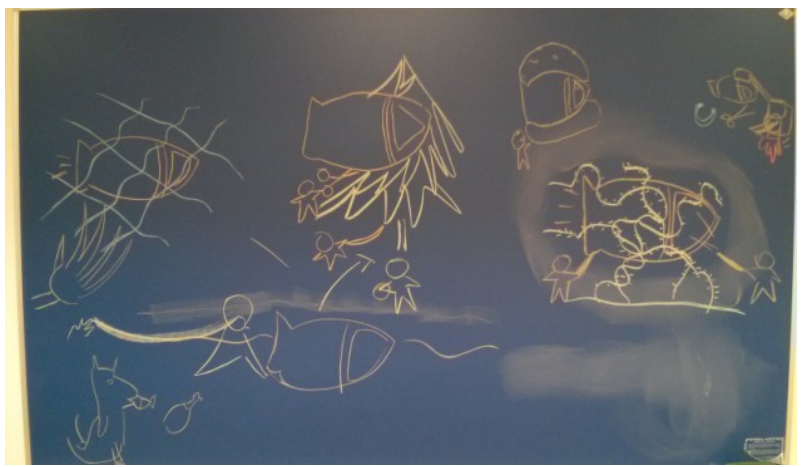

Figure 6. Blackboard during directed design 


\subsection{Fifth session}

The fifth session had the objective of analyzing which elements of the whole gameplay received the biggest attention from children and defining idea for the resolution chapter. Children were asked to draw the story of the game in a storyboard format, on large squares of paper (Fig. 7), according to what they remembered of each chapter. After that each scene was summarized and drawn in the blackboard by a researcher through the directed design method. Finally we explained to them that the character had finally found its friend and was now going to celebrate the reunion. Children were asked to draw this last scene and directed design was used to visualize their proposals. In this context, the researcher also suggested some ideas to evaluate our initial proposal about how to design the final level.

\subsubsection{Observations}

The technique of the "recalling storyboard" was particularly effective in terms of its capability to quickly figure out, according to the children, which are the most relevant aspects of the game and therefore focus our design choices. However, the method was not particularly enjoyable for children and one of them refused to finish his storyboard, since he complained that he had already drawn these things. For future works it will be necessary to enhance the playful aspect of this activity in order to make it more appealing and engaging. At the same time, the use of directed design, allowed to modify our proposals. Our initial idea was to set the final level in a "jelly world". However children were not motivated by this idea and proposed urban environments. Therefore we decide to discard our proposal to include their interests and contributions in the design of the final level.

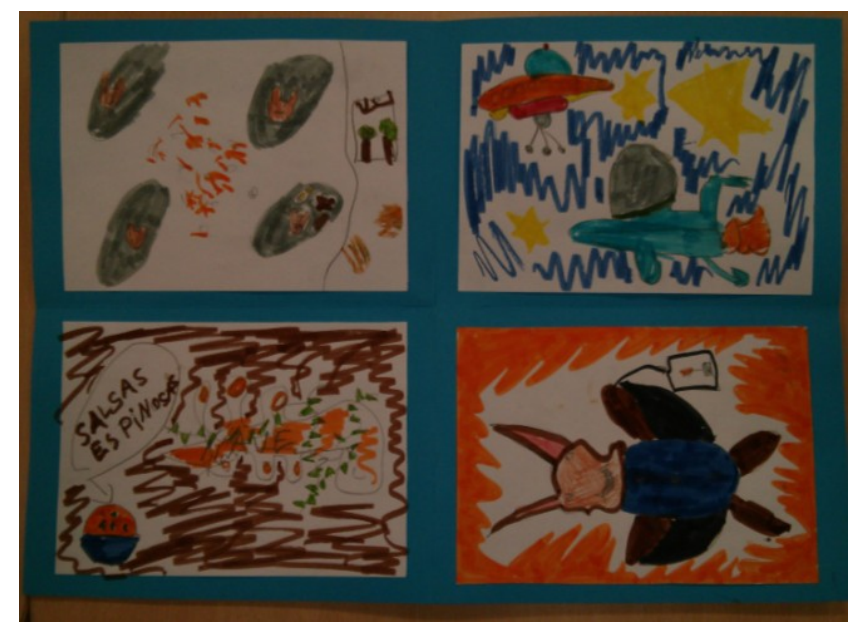

Figure 7. "Recalling storyboard" produced by one child

\section{INTEGRATING CHILDREN'S CONTRIBUTIONS}

The use of participatory design allowed us to understand the preferences of children, validating some initial design proposals, gathering new ideas and evaluating which aspects elicit a higher level of motivation and engagement. Within that, particularly useful insights came from the fundamental role of the audiovisual culture of children as a mediator for the interaction metaphors. Moreover, specifications about character behavior, enjoyable game mechanics, intuitiveness of the interaction, visual and narrative aspects were defined.
Since the project arose from specific requirements defined by the UETD professionals, the integration of children's contributions into the final design was carried out by using learning goals and technological constraints as criteria for selecting the design choices. However, the use of a narrative structure, both in requirements elicitation with psychologist and in the PD with children, facilitated a common directionality of the contributions. This therefore reduced the effort of merging different perspectives.

Currently a digital prototype of the game is under development (Fig. 8). This prototype will be evaluated together with the children that participated in the workshops in order to evaluate if our proposal meets their expectations and elicit novel feedback. This analysis will allow us to implement a new iteration that will then be tested with the target population (5-6 years old children with ASD) in order to evaluate the suitability of the experience for this target age and define eventual refinements. Finally, the game will be assessed for its effectiveness in promoting social initiation skills in the target population.

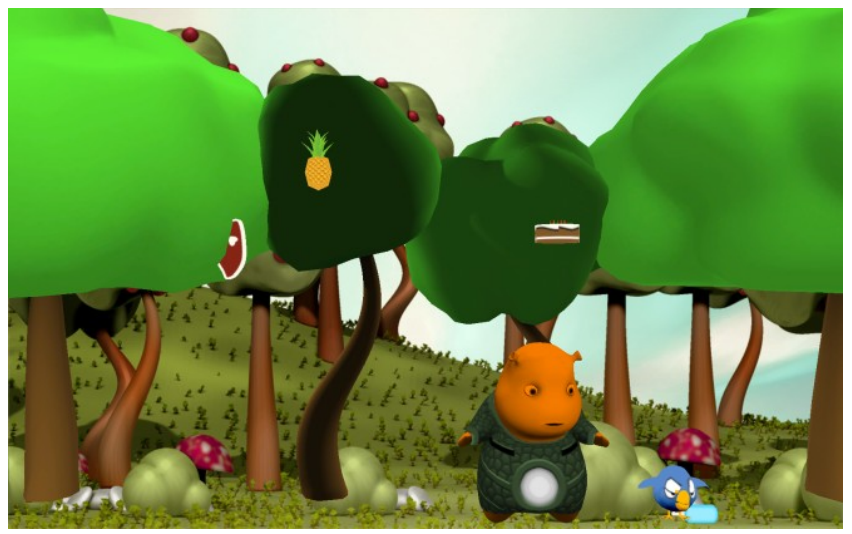

Figure 8. First level prototype

\section{DISCUSSION}

\subsection{Entrusting and empowering ASD children's contributions}

A particularly relevant finding was that children were much more engaged in activities that provided them enough space for personal interpretations and creative contributions. Such tendency was observed from the first session where children preferred to use blank papers instead of pre-designed templates for the exercise of "causal tables". It was also confirmed in the fourth session, where the use of blank paper to design the planet and the game's mechanics elicited a larger number of creative contributions.

This finding partially exceeded our initial expectations and contrasted with related works that report on the use of PD with high functioning autistic children. Related literature suggests the need for highly structured approaches for PD with ASD children and proposes activities in which children's contributions are often limited to very discrete and concrete aspects $[12,16,20]$. From this approach, we initially designed the first session according to a highly directive model, which clearly delimitated the space for children's contributions to concrete elements (e.g. food selection, outfit of the character, etc.). However, from the beginning of the sessions it was clear that children were particularly participative 
and collaborative when faced with activities that give them the possibilities of proposing their own ideas and creations.

A possible explanation of this tendency can be found in the fact that these activities allowed children to feel proud of their productions and to have the perception that their contributions were relevant, valuable and unique. Indeed, children were very proactive in explaining novel ideas to the researchers and, at the end of some sessions they even asked to go to show their artworks to their parents.

Despite several studies point out the potential benefits of PD activities for the empowerment of ASD children [13], it is important to analyze how empowering some of the proposed activities really are. For example, many activities become repetitive exercises which are not only not empowering, but even diminish the present and future creative capabilities of children. We must therefore adopt a critical perspective when choosing these activities especially for ASD children. Such perspective requires analyzing the relation between the expectations of researchers, meaningfulness of the activity for the children and their perceived feeling of competence.

\subsubsection{Researcher's expectations}

As our experience suggests, our initial expectations were exceeded by the level of creative contributions of the children. Such findings indicate how possible bias in the initial expectations of the researcher can be detrimental for properly designing PD activities. It is therefore necessary to assume an approach that goes "beyond expectations". This implies being highly receptive to children's affective states and constantly adapting to the current situation and context. An effective strategy to address this aspect was the continuous evaluation of the meaningfulness of the activities, its suitability and the children's feeling of competence.

\subsubsection{Meaningfulness and feeling of competence}

Our observations showed how the use of the game backstory was particularly useful for making children care about what they were doing. The appeal of the alien's story fostered their interest for being active producers of its adventures. Several "sub-stories" were proposed even without the instructions of the researcher.

At the same time, the chapter structure and boxes showed to be effective in fostering children's feeling of competence. The possibility of tracking one's own achievement and seeing them recognized is fundamental to foster the feeling of competence [22]. The chapter structure facilitates conditions for which children can see their contributions reflected in the ongoing story. This feeling was strengthened by making their contributions explicit; e.g. "as you said last week, we have now incorporated this element".

The use of boxes was particularly useful for children self-tracking of their progress. Children quickly get used to storing their material in the boxes and often they take their previous works as reference for novel contributions. Indeed, a strong example was seen when in the last session a child became quite disappointed when he noticed that the large format storyboard did not fit in his box. This suggests the importance of having a container for all his artworks.

These observations showed how combining a meaningful context with the feeling of competence facilitated conditions for enabling children and researchers to create together. Moreover, they suggest the necessity of researchers to truly entrust the skills of children in order to allow them to feel capable and skilled. In this context, an interesting finding, as the psychologist pointed out, was that, despite two of the children were not used to draw (as noted in their records), they all easily engaged with the activities based on drawing.

Such approach, oriented toward fostering the "empowerment dimension" of the activities, can enhance the potential benefits of PD activities both for the children themselves and for design purposes. Furthermore "the empowerment dimension" does not only influence the immediate response during the workshop but can also have long term implications related with children selfefficacy. The reinforcement of the idea that they are "capable of designing a videogame" highly motivated children, and two of them asked us for references and software to start developing their own videogames at home.

\subsection{Designing activities: the balance between structure and freedom}

The tension between structure and freedom represents a critical aspect in the design of all kinds of educational interventions [1]. Such relation acquires even greater importance when we design activities for children with ASD. As literature suggests highly unstructured activities may be distressing for these children [20]. However, as our experience suggests, excessive constrains can be counterproductive in terms of children participation and involvement.

Finding a proper balance between structure and freedom represents therefore a delicate task. It cannot be simplified to reducing the contributions of children to some very limited and discrete aspects, since this approach can reduce children's willingness to participate. To address this issue, during the workshop we implemented a set of transversal "structuring techniques" aimed at avoiding overwhelming them while giving them space for participation. Such techniques were: the use of the narrative structure, the constancy of the setting and the use of a visual schedule.

As previously stated the use of narrative showed to be an effective instrument both from the point of view of activity capability and in terms of children enjoyment and empowerment. Furthermore this method allowed us to find a proper balance between orienting children's contributions toward our design question, clearly defining the scope of the activities and giving enough space for creation. More concisely, through the use of narrative we had been able to provide children with scenarios that frame the activity without constraining their creativity. The shared experience that children had with storytelling [18] allowed them to move in a secure and known ground, which was at the same time structured enough to avoid being overwhelmed by starting from scratch, and sufficiently motivating to foster their engagement and willingness to contribute.

Another useful technique to facilitate the balance between structure and freedom was the clear definition of the setting. That is, that the time, space and norms in which the workshop took place should be maintained as constant as possible. A clear evidence of the importance of the constancy of the setting was the disruption of the usual dynamics produced by the absence of two children in the third session. This evidence is supported by traditional psychological practice, according to which this constancy strongly contributes to generate a secure and safe space to enable participation.

Finally, in the first session we used a visual schedule to inform the children about the upcoming activities. Despite we believed that 
this method would allow children to feel more secure by knowing what would happen, after the first session we decided to avoid the use of the schedule because we noticed that it was influencing children responses.

According to our experience the role of structure should not be interpreted as reducing the space for children's contributions. It is rather an instrument to generate conditions for which children can safely explore, play and create with the researchers.

\section{CONCLUSIONS}

The paper presented a participatory design workshop with ASD children aimed at integrating their contributions into the design of a Kinect-based game. The workshop had the goals of defining game mechanics that could be enjoyable for children and specifying game features.

At a methodological level the workshop was based on the use of the educational design research approach, understood as the continuous evaluation and adjustment of the proposed activity according to children responses. This method allowed us to widen the space for children's contributions and redefine their level of involvement, with benefits both from the design point of view and from the children themselves.

Such approach was supported by a careful evaluation of the "empowerment dimension" of the proposed activities, formalized as the extent to which children care about what they are doing (meaningfulness) and their perception about the relevance and importance of their contributions (feeling of competence). The analysis of this dimension allowed identifying some useful approach to strengthen children's empowerment and consequently fostering their participation. Main benefits were found in the use of narrative as an instrument both for empowering and providing a proper balance between structure and freedom. At the same time choices related with contextual and material aspects such as the constancy of the setting and the use of personal storage boxes, showed to be highly effective supports for PD activities with ASD children.

Our experience suggests the possible benefits of widening the space for children contributions. However, it is necessary to acknowledge that our findings are based on a reduced group of children and therefore cannot be generalized until additional follow-up studies are carried out. Nonetheless, a fundamental aspect that can be highlighted is that, when designing with children with ASD, it becomes crucial for researchers to be able to deal with a complex network of variables that range from socioaffective aspects to functional constraints. This approach requires going "beyond expectations". Moreover, it also requires being capable of assuming a situated perspective, in which understanding children's affective state represents a fundamental factor for properly designing activities that are both useful for design and enjoyable and empowering for children.

\section{ACKNOWLEDGMENTS}

We would like to thank the professionals of UETD for their support and collaboration and the four children who participated in the workshop.

\section{REFERENCES}

[1] Ackermann, E. 2004. Constructing knowledge and transforming the world. In M. Tokoro and L. Steels, eds., $A$ learning zone of one's own: Sharing representations and flow in collaborative learning environments. IOS Press.

[2] Anamaria, P., Simut, R., Pintea, S., Saldien, J., et al. 2013. Can the social robot probo help children with autism to identify situation-based emotions? A series of single case experiments. International Journal of Humanoid Robotics 10,3 .

[3] Association., A.P. 2000. Diagnostic and statistical manual of mental disorders. 4 th ed.

[4] Benton, L., Johnson, H., Ashwin, E., Brosnan, M., and Grawemeyer, B. 2012. Developing IDEAS : Supporting children with autism within a participatory design team. In Proceedings of the SIGCHI Conference on Human Factors in Computing Systems (CHI '12). ACM, New York, NY, USA, 2599-2608. DOI $=10.1145 / 2207676.2208650$ http://doi.acm.org/10.1145/2207676.2208650

[5] Cobb, S., Parsons, S., Millen, L., Eastgate, R., and Glover, T. 2010. Design and development of collaborative technology for children with autism: COSPATIAL. INTED2010 International Technology, Education and Development Conference.

[6] Dindler, C., Eriksson, E., Sejer, O., et al. 2005. Mission from Mars - A Method for Exploring User Requirements for Children in a Narrative Space. In Proceedings of the 2005 conference on Interaction design and children (IDC '05). ACM, New York, NY, USA, 40-47. DOI $=10.1145 / 1109540.1109546$ http://doi.acm.org/10.1145/1109540.1109546

[7] Dindler, C. and Iversen, O.S. 2007. Fictional Inquirydesign collaboration in a shared narrative space. CoDesign. 3,4, 213-234

[8] Druin, A. 1999. The Role of Children in the Design of New Technology. Behaviour and information technology, 21,1, 125

[9] Farrell-Kirk, R. 2001. Secrets, symbols, synthesis, and safety: The role of boxes in art therapy. American Journal of Art Therapy, 39, 3.

[10] Frauenberger, C., Good, J., Alcorn, A., and Pain, H. 2012. Supporting the design contributions of children with autism spectrum conditions. In Proceedings of the 11th International Conference on Interaction Design and Children (IDC '12). ACM, New York, NY, USA, 134-143. DOI=10.1145/2307096.2307112 http://doi.acm.org/10.1145/2307096.2307112

[11] Frauenberger, C., Good, J., and Alcorn, A. 2012. Challenges, opportunities and future perspectives in including children with disabilities in the design of interactive technology. In Proceedings of the 11th International Conference on Interaction Design and Children (IDC '12). ACM, New York, NY, USA, 367-370. DOI=10.1145/2307096.2307171 http://doi.acm.org/10.1145/2307096.2307171

[12] Frauenberger, C., Good, J., and Keay-Bright, W. 2010. Phenomenology, a framework for participatory design. In Proceedings of the 11th Biennial Participatory Design Conference on - PDC '10, 187.

[13] Frauenberger, C., Good, J., and Keay-Bright, W. 2011. Designing technology for children with special needs: bridging perspectives through participatory design. CoDesign $7,1,1-28$. 
[14] Fullerton, T. 2008. Game Design Workshop: A Playcentric Approach to Creating Innovative Games. Morgan Kaufmann

[15] Guha, M.L., Druin, A., and Fails, J.A. 2008. Designing with and for children with special needs : An inclusionary model. In Proceedings of the 7th international conference on Interaction design and children (IDC '08). ACM, New York, NY, USA, 61-64. DOI=10.1145/1463689.1463719 http://doi.acm.org/10.1145/1463689.1463719

[16] Keay-Bright, W. 2007. The Reactive Colours Project: Demonstrating Participatory and Collaborative Design Methods for the Creation of Software for Autistic Children. Design Principles \& Practices: An International Journal 1, 2.

[17] Kozima, H., Nakagawa, C., and Yasuda, A. 2005. Interactive robots for communication-care: a case-study in autism therapy. In Robot and Human Interactive Communication. ROMAN 2005. IEEE International Workshop, 341-346. IEEE.

[18] Losh, M. and Capps, L. 2003. Narrative Ability in HighFunctioning Children with Autism and Asperger's Syndrome. Journal of Autism and Developmental Disorders. 33, 3, $239-251$.

[19] Mazzone, E., Tikkanen, R., Read, J.C., Iivari, N., and Beale, R. 2012. Integrating children' $s$ contributions in the interaction design process. International Journal of Arts and Technology. 5, 2, 319-346

[20] Millen, L., Cobb, S.V.G., Patel, H. 2010. Participatory design with children with autism. In Proceedings 8th Intl. Conference on Disability, VR and Associated Technologies, Valparaiso, Chile. 93-101.

[21] Mora, J., Malinverni, L., and Pares, N. 2014. NarrativeBased Elicitation: Orchestrating Contributions from Experts and Children. In Proceedings of the SIGCHI Conference on Human Factors in Computing Systems (CHI '14).In press

[22] Muñoz Garcia, A. 2010. Psicologia del desarrollo en la etapa de educacion primaria. Ediciones Pirámide, S.A.
[23] Nesset, V. and Large, A. 2004. Children in the information technology design process: A review of theories and their applications. Library \& Information Science Research, 26(2), 140-161.

[24] Parés, N. and Altimira, D. 2013. Analyzing the Adequacy of Interaction Paradigms in Artificial Reality Experiences. Human-Computer Interaction 28, 2, 77-114.

[25] Peeters, T. 2006. L'autisme. De la compréhension à l'intervention. Paris: Dunod.

[26] Porayska-Pomsta, K., Frauenberger, C., Pain, H., Rajendran, G., Smith, T., Menzies, R., Foster M.E. 2012. Developing technology for autism: an interdisciplinary approach. Personal and Ubiquitous Computing. 16, 2 , 117-127.

[27] Riviere, A. 2001. Autismo: Orientaciones para la Intervención Educativa. Ed. Trotta

[28] Roeyers, H. 1995. A peer-mediated proximity intervention to facilitate the social interactions of children with a pervasive developmental disorder. British Journal of Special Education $22,161-164$.

[29] Sansosti, F. and Powell-Smith, K. 2008. Using ComputerPresented social stories and video models to increase the social communication skills of children with highfunctioning autism spectrum disorders. Journal of Positive Behaviour Interventions. 10, 3, 162-178.

[30] Scaife, M. and Rogers, Y. 1999. Kids as Informants : Telling us what we didn' $t$ know or confirming what we knew already? In A. Druin, ed., The design of children's technology. 1-26.

[31] Strickland, D., Marcus, L., Mesibov, G., and Hogan, K. 1996. Brief report: Two case studies using virtual reality as a learning tool for autistic children. Journal of Autism and Developmental Disorders. 26, 6, 651-660.

[32] Van den Akker, J., Gravemeijer,K., McKenney,S., and Nieveen, N. 2006 Educational design research. Routledge. 